\title{
The Current Legislative Landscape for Maternal and Infant Health and Why It Matters
}

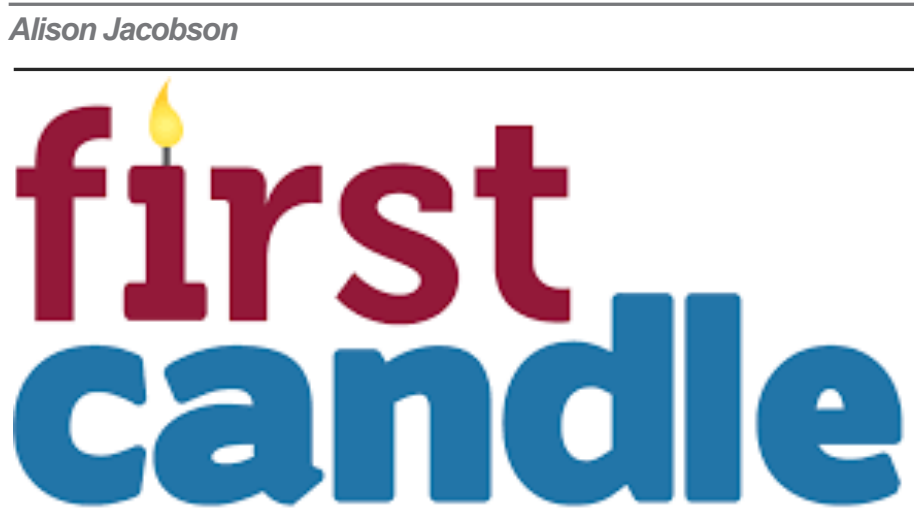

Saving babies. Supporting families.

First Candle's efforts to support families during their most difficult times and provide new answers to help other families avoid the tragedy of the loss of their baby are without parallel.

\section{Abstract:}

Background: About 3,500 infants die annually within their first year of life from Sudden Unexplained Infant Death (SUID) and its subset Sudden Infants Death Syndrome (SIDS), making it the single leading cause of infant mortality in the U.S. Evidence indicates adherence to infant Safe Sleep Guidelines developed by the American Academy of Pediatrics (AAP) reduces these mortality rates. Still, since an initial decline following the 1994 guidelines introduction, SIDS rates have leveled, and SUID rates have increased. In addition, SUID rates per 100,000 live births are twice as high among Black and Native American infants than white. The AAP last updated the guidelines in 2016 and is scheduled to issue the next updated guidelines in late 2021.

Objective: To examine perceptions of the AAP guidelines held by parents and health care providers as they relate to guidelines comprehension and compliance, and to share this information with the AAP 2021 guidelines task force.

Methods: First Candle commissioned a qualitative research study in 2020, consisting of three online focus groups in three differ- ent states to identify perceptions and potential barriers to guidelines adoption by family members and providers, the outcomes of which were shared with the AAP for review as its guidelines task force develops the updated version to be released in 2021.

Results: Regarding how the AAP guidelines were viewed, there were responses across geographic and sociocultural variation regarding varying levels of general comprehension and trust in them, depending on the resource and acceptance of the language used. Additional factors were the emotional and practical realities of parenting, cultural and family traditions, and the belief that parental volition in decision-making is important.

Conclusion: Evidence-based protocols regarding infant safe sleep practices and their impact on reducing infant mortality rates may have proven value. Still, professional caregivers and family members feel that more cultural context and personal relevance are needed in presentation and communication if families are to trust and consider them for adoption and compliance.

\section{Keywords:}

infant mortality, infant safe sleep, implicit bias, Sudden Unexplained Infant Death (SUID).

\section{Definition of terms:}

Qualitative research: Information gathered first-hand regarding individual feelings, opinions, and perceptions, through focus group questions and discussion. The information is not quantified.

Purposive: qualitative research conducted with a sampling whose characteristics indicate it will likely have knowledgeable responses to the topics to be introduced.

Infant Safe Sleep Guidelines: the evidence-based recommendations developed by the American Academy of Pediatrics Task Force, to reduce the risk of Sudden Unexplained Infant Death, including Sudden Infant Death Syndrome and Accidental Suffocation and Strangulation in Bed (ASSB). The current revision in use was released in 2016 .

Implicit bias: bias that can occur automatically, without conscious thought.

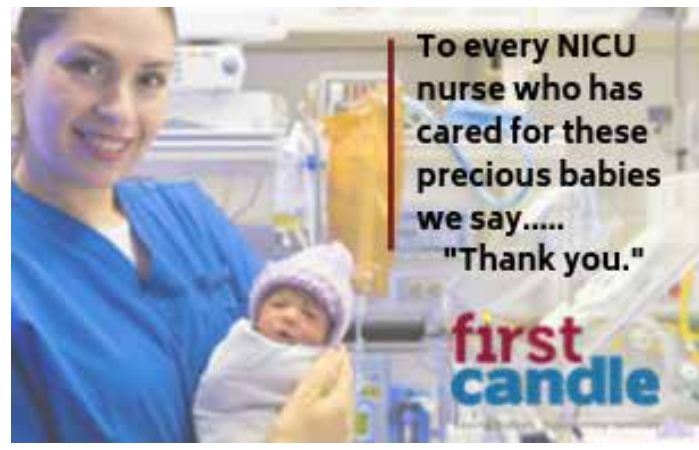

\section{Did you know that premature and low birth weight babies have a $4 \times$ greater risk for SIDS?}

At First Candle we're educating parents, grandparents and caregivers about safer sleep to make sure all babies reach their first birthday. Learn more at firstcandle.org 
"The final content of the Biden Administration's Build Back Better Act is currently being worked out in budget reconciliations in Congress, and at stake are several initiatives that could affect maternal health - and, therefore, infant health."

The final content of the Biden Administration's Build Back Better Act is currently being worked out in budget reconciliations in Congress, and at stake are several initiatives that could affect maternal health - and, therefore, infant health.

- $\quad$ The plan includes provisions to increase and diversify the perinatal workforce, including education and anti-bias training for healthcare providers.

- It also calls for improvements in data collection to better understand the causes of maternal mortality and complications from birth and investments in community-based organizations.

- It proposes making the American Rescue Plan's health insurance premium reductions permanent for women who buy it on their own, an annual savings of $\$ 600$.

- In addition, those covered by Medicaid and CHIP would receive a full year of postpartum coverage, regardless of which state they live in. The bill would require all states to extend full-benefit Medicaid and CHIP postpartum coverage to one year by redefining the postpartum period from 60 days after pregnancy to 12 months.

Several of the maternal health-related investment proposals were advanced by the Black Maternal Health Momnibus, (1) a package of bills created in the U.S. House of Representatives to drive multi-agency efforts to improve maternal health, particularly among racial and ethnic minority groups, and which continues to be advocated for during the reconciliation process.

A state version, the California Momnibus Act, was signed into law in October 2021 by Governor Newsom and includes Medi-Cal coverage for doulas, extending Medi-Cal eligibility for postpartum people, providing easier access to CalWORKs for pregnant people, and establishing a guaranteed income pilot program that prioritizes pregnant Californians with low incomes.

These proposed investments matter for several reasons. Maternal mortality rates in the U.S. are among the highest in the developed world and especially high among Black and Native Ameri- can women (2), regardless of income or education levels. Being aware of maternal and infant health, including access to healthcare throughout the pregnancy and breastfeeding, is an important component of the infant safe sleep practices advised by the American Academy of Pediatricians, which form a basis of the educational outreach First Candle has been undertaking for more than 30 years. Healthy mothers, healthy pregnancies, and healthy babies can contribute to decreased risk for Sudden Unexpected Infant Death (SUID), which remains the leading cause of death in children between one month and one year of age.

\section{"In addition to potentially boosting GDP and the jolb market, the administration believes increasing women's labor force participation is critical to supporting working families, including the over 4 in 10 mothers, mostly women of color, who are the sole or primary wage earners in their families."}

The proposed act also examines the economic universe women operate in and its impacts on their health and wellbeing. One of these areas is to increase compensation for childcare and home care workers. Roughly 90 percent of care workers are women, and nearly half of childcare workers are women of color. (3) On average, childcare workers make 23 percent below workers who do not work in that profession. (4) The proposed plan would ensure childcare and preschool teachers are paid at least $\$ 15$ an hour and comparable to kindergarten teachers if they possess similar credentials.

In addition to potentially boosting GDP and the job market, the administration believes increasing women's labor force participation is critical to supporting working families, including the over 4 in 10 mothers, mostly women of color, who are the sole or primary wage earners in their families.

Unfortunately, National Paid Family and Medical Leave is at risk of being cut from the budget. Today, one in three Americans - estimated at 113 million -- lack access to a single day of paid leave to care for themselves or their loved ones. This population is overwhelmingly women, communities of color, and low-wage working families. And one in four women goes back to work two weeks after giving birth. The ability for mothers to recuperate postpartum and remain home to care for their baby is critical to the health and wellbeing of both mother and child. At the time of this writing, members of Congress are still negotiating the budget package.

NEONATOLOGY TODAY is interested in publishing manuscripts from Neonatologists, Fellows, NNPs and those involved in caring for neonates on case studies, research results, hospital news, meeting announcements, and other pertinent topics. Please submit your manuscript to: LomaLindaPublishingCompany@gmail.com 
They must hear from all of us to make sure they pass a national paid family and medical leave program.

Regardless of the final decisions made in the Build Back Better plan, the relevant issues it raises and hopes to address are the result of efforts by those at the local, state, national, and organizational levels who are aware of the link between family health, maternal health, and infant health, and how day-to-day living and systemic practices that weaken access to health care can contribute to health disparities. Their importance will not go away after the plan is finalized, and whatever issues remain unaddressed should continue to be fought for.

\section{References:}

1. https://www.congress.gov/bill/117th-congress/house-bill/959

2. https://www.cdc.gov/nchs/pressroom/nchs press releases/2020/202001 MMR.htm

3. https://nwlc.org/wp-content/uploads/2020/08/ChildCareWorkersFS.pdf

4. $\quad$ https://www.epi.org/publication/child-care-workers-arentpaid-enough-to-make-ends-meet/

Disclosure: The author is the Executive Director and Chief Executive Officer of First Candle, Inc., a not-for-profit 501c3 corporation.

NT

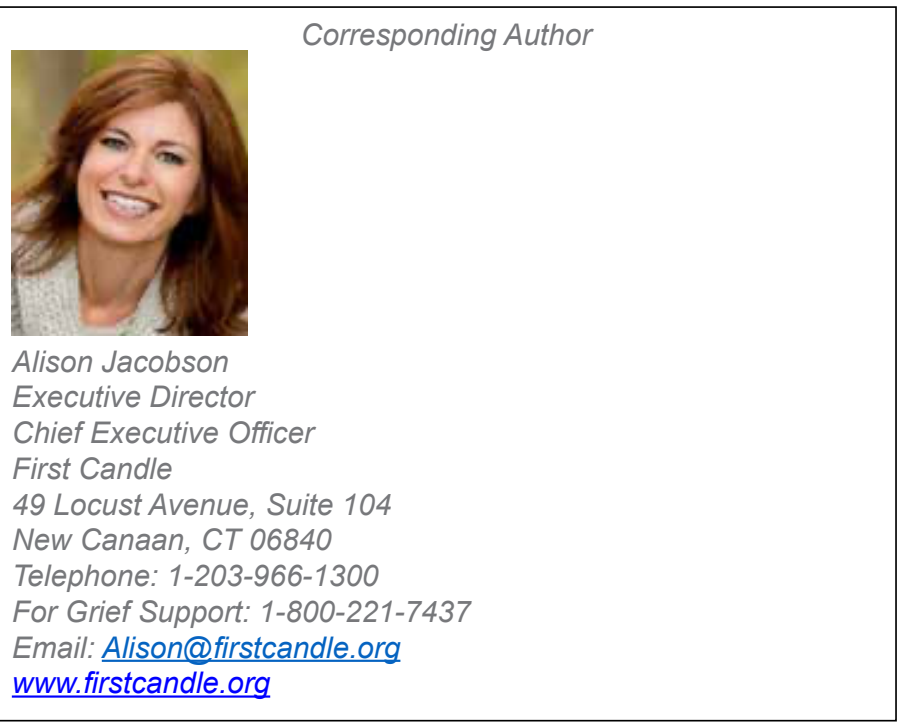

\section{About First Candle}

First Candle, based in New Canaan, CT, is a 501c (3) committed to eliminating Sudden Infant Death Syndrome and other sleeprelated infant deaths while providing bereavement support for families who have suffered a loss. Sudden unexpected infant death (SUID), which includes SIDS and accidental suffocation and strangulation in bed (ASSB), remains the leading cause of death for babies one month to one year of age, resulting in 3,600 infant deaths nationwide per year.

\section{How to Prevent RSV}

\section{RESPIRATORY SYNCYTIAL VIRUS}

RSV IS A SEASONAL RESPIRATORY

VIRUS that can be dangerous for some

babies and young children.

RSV is the leading cause of hospitalization for babies under age 1.

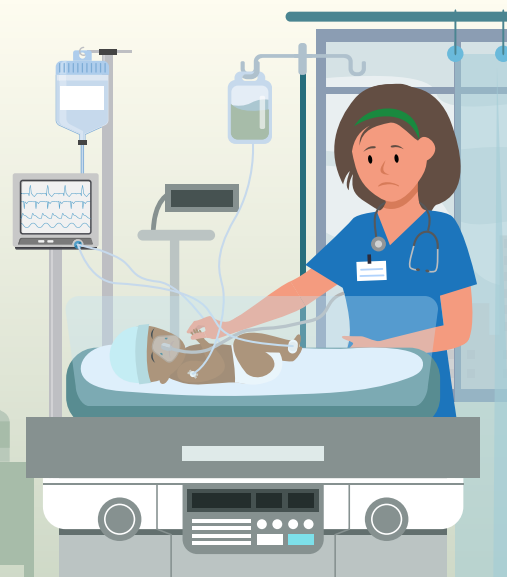

Good hygiene \& cleaning practices can help prevent $R S V$.
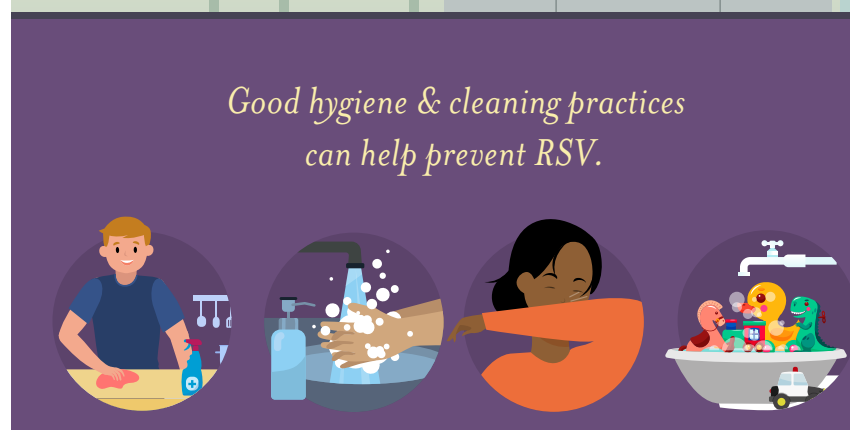

Sanitize surfaces frequently

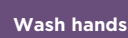

often
Cover coughs and sneezes
It's important to protect your baby

from unnecessary risks during $R S V$ season.
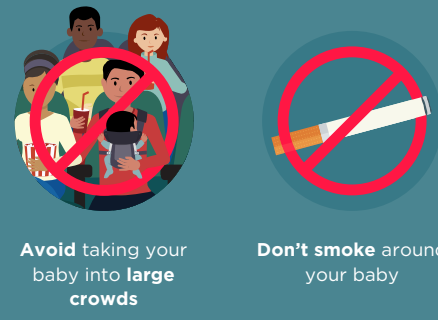

Don't smoke around your baby

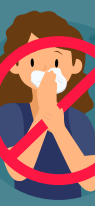

Avoid contact

with sick people NCfIH $\begin{aligned} & \text { National Coalition } \\ & \text { for Infant Health }\end{aligned}$ LEARN MORE । 